\title{
Identification of the Strike-Slip Faults in Central Junggar Basin and Discussion on Its Petroleum Geological Significances
}

\author{
Shuhua Wang1,2, Weiwei Li² \\ ${ }^{1}$ China University of Petroleum, Beijing \\ ${ }^{2}$ Western New Prospect Research Center, Shengli Oil Field, Dongying \\ Email: 420929126@qq.com \\ Published on Advances in Geosciences, Vol. 4, No. 6, 2014; available on \\ http://www.hanspub.org/journal/PaperInformation.aspx?paperlD=14632
}

\begin{abstract}
The Central Block 2 of Junggar Basin is located in the center of the basin, whose Jurassic fractures were considered to be characterized by reverse fault. However, from the recent studies with the methods of coherent and curvature, they showed that the "flower" structure developed at Jurassic showing a "Y" type in seismic section. The fractures spread in "Yan Line" (the shape is the flying wild goose) in plane, and have "dolphin" effect in space. Therefore, it was suggested that the Jurassic fractures were dominant by dextral strike-slip fault. This finding had great significance in improving hydrocarbon reservoirs exploration and trap evaluation in this area
\end{abstract}

\section{Keywords}

Flower Structure, En Echelon Distribution, “Dolphin” Effect, Right-Lateral Strike-Slip 